\title{
Educação Financeira com Idosos em um Contexto Popular
}

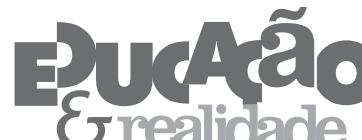

\author{
Caroline Stumpf Buaes \\ 'Faculdade Meridional (IMED), Passo Fundo/RS - Brasil
}

RESUMO - Educação Financeira com Idosos em um Contexto Popular. Este artigo discute o consumo entre idosos de classes populares no contexto brasileiro e a importância de pensarmos intervenções educativas destinadas a esta população. A discussão deriva de uma pesquisa de caráter participante, desenvolvida por meio de uma ação pedagógica realizada com mulheres idosas, fundamentada em princípios da educação popular e da abordagem histórico-cultural. Os resultados sinalizaram que as participantes produziram coletivamente estratégias de controle financeiro e novas construções conceituais dos mecanismos do crédito consignado. Por fim, propõem-se alguns princípios para a criação de práticas de educação para o empoderamento e protagonismo do consumidor idoso.

Palavras-chave: Educação Financeira. Envelhecimento. Consumo. Educação de Adultos e Idosos.

ABSTRACT - Financial Education for the Elderly in a Low-Income Context. This article discusses consumption among Brazilian low-income elderly people and the importance of considering educational interventions designed for this population. The discussion stems from a participant observation research, developed by means of a pedagogical action performed with elderly women, founded on popular educational principles and cultural-historical approach. Results showed that the participants collectively produced financial control strategies and new conceptual constructions of consigned credit mechanisms. Lastly, some principles advocate the generation of educational practices that promote empowering and protagonism among elderly consumers.

Keywords: Financial Education Ageing. Consumption. Adult and Elderly Education.

Educação \& Realidade, Porto Alegre, v. 40, n. 1, p. 105-127, jan./mar. 2015. 


\section{Introdução}

No contexto brasileiro, nos últimos anos, novos consumidores foram descobertos por meio da ascensão das classes populares para as camadas médias e do aumento do poder de consumo de idosos. Essa transformação anima a economia e desperta o interesse para o surgimento de negócios voltados a atender as demandas desses segmentos. Nesse sentido, os idosos dos grupos populares vêm sendo vistos no Brasil como novos consumidores.

A melhora da condição financeira dos idosos também passou a despertar especial interesse de diferentes instituições financeiras. Os órgãos bancários, através de suas publicidades, atraem milhões de idosos a cada ano para a contratação de créditos, sobretudo o consignado, levando ao crescente endividamento da população. Nesse cenário se torna importante pensar em intervenções educativas destinadas a esta fatia da população, potencialmente mais vulnerável por suas condições de idade, de baixa escolaridade e de classe social.

Embora os dados da PNAD/2009 mostrem uma redução do analfabetismo em todas as idades, inclusive na faixa de 40 anos e mais, ainda assim há um grande contingente de analfabetos nesta faixa etária: cerca de 16,5\% (IPEA, 2010). Tendo em vista este panorama, é imprescindível que as estratégias didáticas utilizadas em ações pedagógicas considerem a participação nas atividades de sujeitos que tenham este perfil, não fazendo da condição de exclusão da escola uma impossibilidade de aprendizagem.

Tendo como preocupação a produção de ações educativas para o consumo com idosos, realizou-se uma pesquisa com mulheres idosas em um contexto popular com o objetivo de analisar os processos de construção coletiva de conhecimentos acerca de práticas de consumo e decisões financeiras. A ação pedagógica foi fundamentada nas ideias pedagógicas de Paulo Freire, que embasam a educação popular, e da abordagem da psicologia histórico-cultural, construída a partir das contribuições de Lev Vigotski.

O texto segue discutindo as problemáticas associadas ao consumo entre idosos no contexto brasileiro, especialmente de crédito consignado, e a necessidade de educar consumidores. Em seguida apresenta o desenho da pesquisa e alguns saberes produzidos pelas idosas no contexto da intervenção. Por fim, o trabalho propõe, ainda, alguns princípios que possam orientar propostas educativas voltadas para o empoderamento do consumidor idoso, no sentido de ampliar suas potencialidades e sua capacidade de intervenção social, quando estes não apenas se apropriam de novos conhecimentos, mas se reconhecem no lugar de sujeitos de saber e de direito ao saber. 


\section{Os Idosos de Classes Populares no Brasil: novos consumidores}

Em razão da vontade de consumir e da facilidade de obter créditos, muitas vezes, a pessoa pode não perceber ou apresentar dificuldades em aceitar suas limitações financeiras. No Brasil, os bancos não apenas oferecem créditos especiais como procuram convencer as pessoas a contratar empréstimos mesmo se estas não têm necessidade. Os idosos de classes populares tendo em vista a melhora de sua condição financeira estão recebendo, cada vez mais, atenção especial dos bancos e empresas financeiras. Essa situação foi provocada, especialmente, pelo aumento dos benefícios sociais nas últimas décadas, dentre os quais se destaca o Benefício de Prestação Continuada da Assistência Social, instituído pela Constituição Federal de 1988.

No Brasil até o início da década de 1990, a imagem social dos idosos foi relacionada à pobreza. Contudo, a partir desse período as pessoas idosas passaram a ter maior importância no cenário do mercado de consumo. Os idosos tornaram-se mais concentrados entre os vulneráveis e os não pobres, graças à vinculação do piso da previdência e do Benefício de Prestação Continuada ao salário mínimo. Esse fato tornou-se, para eles e para os membros de seu grupo doméstico, um seguro contra a pobreza extrema, ou mesmo contra a pobreza.

Conforme dados do IBGE (2010), em 2009, 64,1\% dos idosos brasileiros eram considerados a pessoa de referência no domicílio (pessoa responsável pela família ou que assim fosse considerada pelos demais membros da família), 30,7\% tinham menos de um ano de instrução e $66 \%$ já estavam aposentados. As estimativas da Pesquisa Nacional de Domicílios (PNAD) de 2011 apontaram para um contingente de aproximadamente 23 milhões de pessoas com 60 anos e mais, o que representa cerca de $12 \%$ da população brasileira, sendo que aproximadamente 15,0 milhões de idosos chefiavam famílias. Destes, 55,4\% eram homens. Dos 5,7 milhões de idosos que estavam na condição de cônjuges, $77,1 \%$ eram mulheres. Em aproximadamente 6,5 milhões de famílias onde o idoso era chefe ou cônjuge, encontravam-se filhos adultos residindo. E em 2,2 milhões, netos. Nas famílias em que o idoso era chefe ou cônjuge com filhos adultos, os idosos contribuíam com $52,9 \%$ da renda familiar. Ou seja, os idosos brasileiros de hoje estão invertendo a tradicional relação de dependência apontada pela literatura. A grande maioria deles tem assumido o papel de provedor, mesmo dependendo de cuidados (IPEA, 2012).

Assim, observa-se o aumento de famílias chefiadas por idosos com filhos e netos residindo no mesmo espaço. $\mathrm{O}$ aumento de auxilio a pessoas que convivem com o idoso torna-se muitas vezes um fator que contribui para o crescimento de dívidas, uma vez que o rendimento regular dos idosos torna-se especialmente importante em um mercado de trabalho precário e instável, marcado pela dificuldade de acesso das gerações mais jovens e pelo trabalho informal (Doll, 2009). Nesse cená- 
Educação Financeira com Idosos em um Contexto Popular

rio, é possível que a contratação de empréstimos seja realizada como tentativa de manutenção tanto das necessidades básicas de sobrevivência como de liquidar dívidas, podendo gerar situação de dependência e exploração financeira do idoso no contexto familiar (IPEA, 2012).

Uma modalidade de empréstimo bastante contratada pelos idosos no Brasil é o crédito consignado, criado em 2003 para as pessoas que recebem aposentadoria através do Instituto Nacional do Seguro Social (INSS). Trata-se da consignação de descontos para pagamentos de empréstimos e cartão de crédito, contraídos nos benefícios da Previdência Social com taxas de juros reduzidas em relação às praticadas no mercado (INSS, 2008). As regras principais são a limitação do número de prestações do crédito (até 60 meses) e os pagamentos mensais, que não podem exceder $30 \%$ do lucro líquido do benefício. Atualmente, as taxas máximas são de 2,14\% ao mês para o empréstimo, e 3,06\% ao mês para o cartão consignado (Brasil, Ministério da Previdência Social, 2013).

Conforme o INSS, em dezembro de 2009 do total de operações de crédito consignado, $75 \%$, foi parcelada de 49 a 60 meses. Quanto à idade dos tomadores dos empréstimos, do total de operações, $36 \%$ foram contratadas por segurados na faixa de 60 a 69 anos e $24 \%$ das operações foram assumidas por aposentados e pensionistas na faixa de 70 a 79 anos (INSS, 2009). Segundo os dados da Previdência Social (2010), o empréstimo pessoal, de 2004 até outubro de 2010 registrou 16,6 milhões de contratos, que somaram $\mathrm{R} \$ 40,9$ bilhões, enquanto o cartão de crédito contabilizou 1,13 milhão de contratos, disponibilizando $\mathrm{R} \$ 498,2$ milhões. Nesse período, o maior número de empréstimos foi efetuado por beneficiários na faixa etária de 60 a 69 anos. A faixa salarial de até um salário mínimo foi a que mais se sobressaiu, com 11,7 milhões de contratos, totalizando R $\$ 21$ bilhões (Brasil, Ministério da Previdência Social, 2010). Portanto, isso significa que o benefício será menor por um bom tempo, podendo alcançar o limite de até cinco anos. O problema é que muitos idosos são surpreendidos com a redução, sendo que a maioria deles não tem uma ideia muito precisa sobre o crédito e as suas especificações.

Existem algumas razões pelas quais os idosos brasileiros de baixa renda utilizam o crédito: fazê-lo para outros membros da família, para melhoria da casa e ainda pagar outras dívidas. Nesse sentido, cabe destacar que o uso do crédito pode criar situações problemáticas. Um exemplo pode ser a geração de dependência dos idosos quando estes tomam um crédito para outras pessoas, engendrando, inclusive, situações de violência (Doll; Buaes, 2008).

Temos que considerar que o crédito, por um lado pôde promover a inclusão das pessoas idosas e de baixa renda no mercado de consumo, mas por outro, também abriu uma possibilidade de exploração das mesmas por parte dos seus próprios familiares e também das instituições financeiras, ainda mais no Brasil onde os as taxas de juros são muito altas. Além disso, a publicidade, o marketing por meio de suas 
estratégias produtoras de desejos, constituem as escolhas dos sujeitos, que consomem créditos, muitas vezes, sem ter uma noção clara do que significa o impacto do mesmo no orçamento dos próximos anos.

\section{Sobreo Consumo eo Endividamento na Contemporaneidadee Necessidade de Educar Consumidores. alguns apontamentos}

Consumir é um imperativo que interpela, cada vez com mais intensidade, os sujeitos a buscarem a satisfação de desejos. É justamente a perspectiva da promessa de satisfação de desejos que move a economia das sociedades contemporâneas. Portanto, a sociedade do consumo para existir precisa da produção dos objetos, mas, sobretudo, necessita da destruição deles para manter-se em movimento.

Assim, a depreciação e a desvalorização dos produtos, logo após terem sido alçados ao universo dos desejos do consumidor são constituintes do processo da constante produção de novos desejos. Nesse contexto, valores de duração e de permanência foram substituídos pela ostentação da qualidade do que é transitório e novo (Bauman, 2008, 2010). Desse modo, é a sensação de não satisfação com o estilo de vida que se tem e que mantém a perpétua busca por prazer que deve vir do meio de bens adquiríveis. O negócio de empréstimos é orientado pela mesma lógica, ou seja, a oferta deve criar e ampliar a necessidade de novos empréstimos, como pontua Bauman ao sinalizar que:

[...] a atual 'contração do crédito' não é resultado do insucesso dos bancos. Ao contrário, é fruto, plenamente previsível, embora não previsto, de seu extraordinário sucesso. Sucesso ao transformar uma enorme maioria de homens, mulheres, velhos, jovens numa raça de devedores. Alcançaram seu objetivo: uma raça de devedores eternos e autoperpetuação do 'estar endividado', à medida que fazer mais dívidas é visto como único instrumento verdadeiro de salvação das dívidas já contraídas (Bauman 2010, p. 31).

O consumo também é impulsionado pelo fato de que cada vez mais as mercadorias possibilitam identidade, pertencimento e reconhecimento social, configurando-se indicadores de distinção entre classes e grupos. Desse modo, as práticas de consumo estão vinculadas a uma identificação do sujeito como pertencentes a determinado estrato social, grupo etário, gênero, estilo de vida dentre outros marcadores de pertencimento social. Os objetos consumidos “[...] manipulam-se sempre como signos que distinguem o indivíduo, quer filiando-o no próprio grupo tomando como referência ideal quer demarcando-o do respectivo grupo por referência a um grupo de estatuto superior" (Baudrillard, 2007, p.60). E, nesse sentido, a capacidade - ou não - de consumir configura-se como critério de inclusão e exclusão social (Costa; Hennigen, 2010).

Educação \& Realidade, Porto Alegre, v. 40, n. 1, p. 105-127, jan./mar. 2015. 
Educação Financeira com Idosos em um Contexto Popular

Essa perspectiva possibilita, conforme sinaliza Canclini (2010), identificarmos uma cumplicidade entre consumo e cidadania na contemporaneidade. Nesse contexto, para Veiga-Neto (2001) são os sentimentos de pertença social - constantemente capturados pelo mercado - que podem conferir a cada pessoa uma posição de maior ou menor presença e atuação na sociedade, capacitando-a para o exercício de uma cidadania mais (ou menos) significativa.

Numerosos são os consumidores que estão constantemente se endividando para consumir produtos e serviços. Dentre os produtos do mercado financeiro que mais facilmente são acessados pela população encontram-se os cartões de crédito e as diferentes linhas de crédito. Portanto, é a sensação de insatisfação e de estar defasado em relação à atualidade das próprias experiências, bem como a busca de pertencimento que impulsionam, muitas vezes, o sujeito a consumir além de duas condições financeiras.

É neste cenário que entram em cena as práticas de educação financeira. Observa-se em diversos países, especialmente a partir do fim do século XX, a emergência de recomendações de governos nacionais para educar os consumidores. De modo geral, essas práticas são implementadas como resposta aos interesses dos Estados e das empresas em expandir os mercados de produtos financeiros, tendo como objeto tanto o consumo de produtos quanto de créditos, seguros e serviços bancários em geral. As principais iniciativas educativas no contexto internacional e brasileiro estão voltadas para cursos de organização de finanças pessoais e investimentos financeiros, para o trabalho em empresas e para a inclusão de temáticas nos currículos escolares e formação de professores.

A partir dessa ótica, segundo Williams (2007), estão sendo produzidos e postos em circulação discursos políticos que classificam o analfabetismo financeiro como um problema que envolve os interesses nacionais e representam a educação financeira como vital para o equilíbrio das economias nacionais. Desse modo, conforme propõe a autora, é de suma importância pensar que em muitos contextos a educação financeira está sendo produzida como um mecanismo de regulação social, no qual o sujeito é responsabilizado por suas escolhas e pela sua segurança financeira. A responsabilização impõe novas exigências aos indivíduos para regular sua conduta e para manter seu bem-estar. Portanto, além de gerir o negócio da própria vida, o trabalho de responsabilização do consumidor se estende para regulação do comportamento das empresas e do desempenho dos mercados.

Alfabetizados financeiramente espera-se que os consumidores qualificados pesquisem o mercado de forma eficaz, acompanhem atentamente as empresas e exerçam poder de expulsá-las do mercado caso sejam desonestas ou indiferentes às necessidades dos consumidores. Assim sendo, temos posta uma concepção de educação financeira que

110 Educação \& Realidade, Porto Alegre, v. 40, n. 1, p. 105-127, jan./mar. 2015 Disponível em: <http://www.ufrgs.br/edu_realidade> 
pretende reforçar as capacidades do consumo responsável para regular a si mesma e a outros agentes do mercado. Dessa forma, a educação financeira pode apresentar uma justificativa para o Estado reduzir o seu investimento em mercados de fiscalização e controle das empresas financeiras, com efeito a aliviar os reguladores das suas responsabilidades para a situação do mercado (Williams, 2007).

Partindo de outra posição, no presente trabalho, apresenta-se a concepção de práticas educativas para o consumo como dispositivos que oportunizem o empoderamento do consumidor, neste caso o idoso. Ou seja, para além do desenvolvimento de habilidades financeiras e da redução de obstáculos à participação no mercado, é preciso oportunizar a acessibilidade das informações e a leitura crítica dos mecanismos que impulsionam o sujeito a consumir, pois assim, torna-se possível tomar uma decisão financeira a partir do entendimento da sua posição nas relações de consumo (Buaes, 2011). Portanto, é imprescindível problematizar os discursos de educação financeira. Quem promove? Com quais interesses? Quais os interesses econômicos e políticos implícitos nos órgãos e instituições que incentivam e patrocinam intervenções?

\section{Método}

Diante da problemática apresentada, tendo como preocupação a construção de intervenções educativas para o consumo com idosos, foi desenvolvida uma pesquisa fundamentada em princípios das metodologias participantes (Brandão, 2006) com mulheres idosas com baixa escolaridade em um contexto popular da cidade de Porto Alegre/RS. Procurou-se analisar os processos de construção coletiva de conhecimentos acerca de suas práticas de consumo e decisões financeiras com a finalidade de propor princípios que orientem ações pedagógicas realizadas com idosos.

As participantes, com idades entre 59 e 78 anos, tinham de um a oito anos de escolarização e uma renda mensal - procedente de aposentadorias, pensões, benefícios sociais e trabalhos domésticos - que não ultrapassa o valor de dois salários mínimos. De forma geral, elas foram chefes de suas famílias e continuam sendo o arrimo financeiro no caso da coabitação com filhos e netos. Nesse sentido, se trata de uma população que se situa na base da pirâmide social do país. Portanto, mesmo que este segmento tenha melhorado de vida e também seja interpelado pelas políticas de consumo, ainda se trata de um público que de certo modo se caracteriza por um consumo de subsistência e tem como objetivo principal chegar ao fim do mês com as contas pagas. Em muitos casos essa situação é ainda agravada pela dependência financeira de filhos e netos que moram com as mulheres. Esses fatores articulados com a idade avançada, que dificulta a geração de rendas extras, impedem a melhoria de suas condições de vida.

Educação \& Realidade, Porto Alegre, v. 40, n. 1, p. 105-127, jan./mar. 2015. 
Educação Financeira com Idosos em um Contexto Popular

A ação educativa foi organizada na forma de um curso em uma instituição de caráter social com duração de dois meses e meios e dois encontros semanais de uma hora e meia a duas horas. Após sete meses do término da intervenção foi realizado um reencontro. A intervenção foi fundamentada nas ideias pedagógicas de Paulo Freire que embasam os princípios da educação popular e da abordagem da psicologia histórico-cultural construída a partir das contribuições de Lev Vigotski.

A construção de conhecimento para Freire é um processo que implica movimento da consciência no sentido de ir e vir à realidade como meio de percepção de si e das suas relações com o outro no mundo. Nesse sentido, justifica-se a importância de lançar mão da ferramenta teórica do campo da psicologia histórico-cultural que possibilite a análise das falas das pessoas e das interações entre elas.

Conforme Poli (2007) os dois campos de conhecimento compartilham da mesma posição teórico epistemológica e política de defesa ao homem como ser em transformação, produto e processo do movimento dialético das relações sociais nas quais se encontra imerso. As formas individuais de consciência, desse modo, têm origem na apropriação das formas coletivas da atividade. Assim, o funcionamento intelectual se forma e se transforma na interação, na troca e no convívio social. Dito de outro modo, a partir desta base, o homem é concebido como ser que se faz pelo trabalho (concepção de trabalho como sinônimo de ato de criar), através dessa ação cria e recria a sua relação com o mundo. Dessa forma, é um homem inconcluso, em processo permanente de devir, do qual é autor e ator.

Nesse sentido, a prática pedagógica foi desenvolvida com a intenção de oportunizar a expressão das significações das experiências existenciais das participantes para que estas pudessem ser (re)significadas. Assim, as estratégias pedagógicas privilegiaram a interação, a discussão e o debate. Partindo das experiências de consumo vividas pelas mulheres procurou-se criar espaços de troca de saberes por meio do diálogo, de forma que novos sentidos acerca de suas realidades pudessem ser produzidos em uma ampliação de sua leitura de mundo.

Para Vigotski (2008a) a origem das funções psíquicas superiores ações conscientemente controladas, atenção voluntária, memorização ativa, pensamento abstrato, ação intencional - está nas relações sociais. Assim, é a partir de sua experiência com o mundo objetivo e do contato com as formas culturalmente determinadas de organização do real e com os signos oferecidos pela cultura que os seres humanos vão construir seu próprio sistema de signos que usarão para a compreensão do mundo.

Segundo a perspectiva de Vigotski (2008b) os signos não se mantêm como marcas específicas dos objetos e nem são usados por indivíduos particulares. Eles passam a serem signos compartilhados pelos membros de um grupo, adquirindo assim um significado que é coletivo 
e compartilhado, permitindo e aperfeiçoando a comunicação e a interação social. Nessa direção, a construção do conhecimento progrediria em direção a uma organização mais complexa a partir daquilo que o sujeito já sabe e das possibilidades que lhe são oferecidas de interação com os pares, educadores e diferentes recursos pedagógicos.

Portanto, o ponto de partida foi o saber já construído a partir da experiência vivida. Assim, no primeiro encontro do curso realizou-se a investigação de temáticas geradoras que se encontravam no cotidiano do grupo. Começamos por meio do levantamento das expectativas em relação ao curso. A primeira inquietação do grupo foi compreender o que é o consignado. Outras questões levantadas pelas participantes também forneceram pistas para a definição de conteúdos para as etapas seguintes do curso, dentre elas: a demanda de compreensão dos mecanismos de juros, das propostas de crédito e do orçamento mensal.

Nessa direção, ao longo dos encontros, levantamos e sistematizamos rendas e despesas; discutimos a importância dos produtos que consumimos para nossas vidas, procurando conhecer os significados que as mulheres atribuíam ao dinheiro e às compras; realizamos a leituras de publicidades procurando compreender como estas nos interpelam a consumir; analisamos publicidades e propostas de crédito consignado e esclarecemos conceitos, como taxas de juros; realizamos exercícios de simulação de contratação de crédito para oportunizar a compreensão dos mecanismos dos empréstimos para uma tomada de decisão consciente das suas condições financeiras bem como o planejamento para os impactos desse nas suas vidas; e, por fim, efetuamos um exercício de orçamento mensal com base nas rendas e despesas identificadas e classificadas no início do curso.

Como já foi explicitado anteriormente, após sete meses da finalização da ação educativa realizamos um reencontro com o grupo com o objetivo de conhecer os efeitos da intervenção. Foram investigadas situações cotidianas nas quais as participantes utilizaram os conhecimentos construídos no curso. Algumas experiências foram narradas e constituíram o marco inicial da análise: escolher prioridades para usar o dinheiro; planejar compras e formas de pagamento; registrar as intenções de compra em um caderno; recusar um crédito consignado para fazer a compra de um computador.

As narrativas do reencontro sinalizaram as aprendizagens consideradas mais significativas, uma vez que se referem à produção de novas respostas a situações de consumo. Entendemos que a participação no curso possibilitou às mulheres produzir novos conceitos, provocando tentativas de mudanças na sua realidade existencial. A partir dos pontos de chegada das novas elaborações conceituais, reconstruímos a trajetória das problematizações das experiências das mulheres com o dinheiro, procurando entender as mudanças cognitivas por meio da análise das interações entre as participantes e as educadoras.

Educação \& Realidade, Porto Alegre, v. 40, n. 1, p. 105-127, jan./mar. 2015. 
Educação Financeira com Idosos em um Contexto Popular

O primeiro procedimento, realizado após a transcrição das gravações das narrativas produzidas no reencontro, foi uma cuidadosa leitura do conteúdo acerca dos eventos de consumo vivenciados após o curso. Procurou-se identificar possíveis efeitos do mesmo na fala das participantes que sinalizassem reflexões sobre as práticas de consumo e sobre as decisões financeiras. A seguir percorreram-se, em um caminho inverso, as interações dos 13 encontros do curso procurando identificar, nas discussões, os elementos que tivessem relação com os conteúdos das falas selecionados do reencontro.

O elemento de descrição de dados foi a interação verbal entre as participantes. Buscou-se no campo da análise da conversação o conceito de turno de fala que foi utilizado na sistematização das interações. Para Marcuschi “[...] turno pode ser entendido como aquilo que um falante faz ou diz enquanto tem a palavra, incluindo aí a possibilidade de silêncio"(Marcuschi, 2003, p. 18). As interações verbais selecionadas para compor o corpus do artigo estão organizadas por conjuntos de falas. As transcrições foram cuidadosamente feitas e obedeceram a uma convenção baseada em Marcuschi (2003) conforme o quadro que segue.

\begin{tabular}{|l|l|}
\hline Convenção & \multicolumn{1}{|c|}{ Significado } \\
\hline$/$ & $\begin{array}{l}\text { Interrupções bruscas (quando alguém tem a fala interrompida } \\
\text { pelo parceiro) }\end{array}$ \\
\hline MAIÚSCULA & Ênfase ou acento forte \\
\hline$(())$ & Comentários da pesquisadora \\
\hline
\end{tabular}

\section{Discussão dos Resultados}

Neste artigo serão mostrados, por meio de alguns exemplos, conhecimentos construídos coletivamente ao longo do curso que oportunizaram a constituição de posturas mais críticas na vida cotidiana das participantes. Estes foram organizados em duas unidades de análise: estratégias de controle financeiro e novas construções conceituais acerca dos mecanismos do crédito e da publicidade. As mulheres construíram estratégias de controle financeiro a partir da reflexão sobre as suas relações com o dinheiro, práticas de consumo e possibilidades financeiras. Além disso, evidenciaram que a compreensão das taxas dos empréstimos, especialmente o conceito de juros, favorece a problematização das estratégias de marketing e da qualidade das informações dos produtos financeiros.

\section{Estratégias de Controle Financeiro}

A análise das interações verbais do reencontro em relação aos eventos ocorridos no decorrer do curso mostrou diferentes estratégias de controle financeiro formuladas pelas mulheres, tais como: analisar os gastos reconhecendo as possibilidades financeiras, planejar o con- 
sumo e guardar dinheiro. Iremos descrever algumas interações que podem ter desencadeado a construção coletiva desses conhecimentos. É relevante destacar que as estratégias derivaram da busca coletiva de solução para duas problemáticas centrais levantadas ao longo do curso: 1) saber quanto se gasta nas compras diárias principalmente no pão de todos os dias e 2) não comprar por impulso, ${ }^{1}$ especialmente com o uso da caderneta, prática comum nas vendas, armazéns e dos vendedores ambulantes do contexto pesquisado.

Os problemas da situação existencial, concreta e presente do grupo e se configuraram como desafios que exigiram respostas no nível da ação. Nesse sentido, as estratégias pedagógicas utilizadas para abordar essas questões foram produzidas com a intencionalidade de conhecer o pensar, a percepção das mulheres sobre as suas realidades e, também, possibilitar que elas mesmas as compreendessem na medida em que propunham soluções para os problemas levantados (Freire, 1987). Estas problemáticas podem ser compreendidas a partir de Freire (1987, 1992) como a percepção de situações limites que produziram demandas de soluções no sentido de interrogar o sujeito em torno de como fazer concreto o inédito viável.

Com o propósito de problematizar as escolhas de prioridades para usar o dinheiro e favorecer a construção de elementos balizadores para a tomada de decisões financeiras, o grupo foi provocado a criar categorias de despesas que pudessem ser aplicadas em diferentes situações do dia a dia. No primeiro encontro listamos despesas do cotidiano das mulheres. A partir dessa atividade produzimos fichas com as despesas listadas que foram utilizadas no segundo encontro quando as participantes deveriam agrupá-las por semelhanças e atribuir um nome a cada conjunto criado. Desse modo, coletivamente construímos três classes de despesas - essencial, necessária (inesperados que não podem esperar) e extra-que foram se constituindo como a base referencial para pensamentos mais complexos.

No decorrer dos encontros também realizamos um exercício de orçamento por meio da sistematização dos valores das rendas e despesas mensais classificadas pelas participantes. A partir da realização do orçamento mensal em um caderno elas puderam apropriar-se de modo mais claro de sua realidade existencial. O registro foi um importante elemento para o reconhecimento de suas condições e possibilidades financeiras e pode ter se constituído, desse modo, como uma estratégia de planejamento e controle financeiro mencionada no reencontro. Vejamos o diálogo abaixo:

Participante 1 Eu pensei antes já do mês passado que com a metade do meu décimo terceiro eu quero comprar um presentinho.

Participante 2 Eu jácomprei o que eu queria comprar.

Educação \& Realidade, Porto Alegre, v. 40, n. 1, p. 105-127, jan./mar. 2015. 
Educação Financeira com Idosos em um Contexto Popular

Participante 1 Eu tenho dois afilhados e três netos. Então eu vou procurar comprar presentes por três netos e mais pros dois afilhados. Eu ainda não comprei ainda. Eu tô pensando e eu tô vendo o que eu posso comprar pra dar pra eles de presente de natal, BEM PENSADINHO.

Participante 2 Então, tem que se programar. Eu já me programei. Não vou sair e na loja eu escolho. Já vai anotadinho, é aquilo ali e deu.

Reencontro

No decorrer das atividades do curso, as participantes tiveram a possibilidade de distanciar-se da própria realidade para olhar para olhá-la de outro modo, isto é, interpretando com as ferramentas do conhecimento que estava sendo construído. O percebido destacado (Freire, 1987) foi a matéria-prima da reinvenção da vida por meio da construção de diferentes estratégias de ação no mundo. Nesse sentido, podemos pensar no orçamento do mês como um conhecimento externo provocado pela pesquisadora-educadora que desencadeou o desenvolvimento dos próprios modelos compreensivos das mulheres de planejamento de compras. Portanto, a construção de conhecimento acontece em um processo no qual o sujeito desenvolve a capacidade de pensar para além do contexto imediato, ampliando a rede cognitiva de significados, de saberes e de compreensão das relações, um processo que Freire (1987, 1992) denomina de ato de admirar a realidade, isto é, a capacidade do sujeito distanciar-se dela como um ato de reflexão sobre sua ação no mundo.

Em diferentes momentos da intervenção educativa, discutimos a importância e as possibilidades de guardar dinheiro. Além da manutenção de um cofrinho em casa, outras estratégias foram sendo inventadas pelas mulheres no seu cotidiano para economizar dinheiro, tais como: procurar fazer as compras do mês em supermercados que são mais econômicos do que os armazéns da vila, evitar o uso das cadernetas e controlar os gastos pingadinhos do cotidiano.

Em relação aos dispositivos pedagógicos que oportunizaram a criação dessas estratégias de controle financeiro, ganhou destaque, no contexto da intervenção educativa, propostas de atividades que desencadearam sentimentos positivos nas mulheres. Estas incentivaram as participantes a experimentá-los na concretude de sua vida, configurando, assim, a vivência de um inédito viável. Como exemplo, podemos citar uma situação em que uma participante relata uma agradável experiência de economizar dinheiro. Essa ação foi mobilizada por uma atitude da pesquisadora-educadora. Vejamos a narrativa: 
Participante 6 Na terça-feira com aquela que a professora falou eu guardei dois reais. Eu gastei um real de pão e estou com outro guardado. Só com o pensamento nela, no que ela me falou.

\section{Encontro 11}

A intervenção da educadora foi a seguinte pergunta: qual a sensação que se tem quando a gente guarda dinheiro, vai lá e compra um pãozinho? Portanto, imaginar-se em uma situação favorável, no caso comprando com dinheiro economizado, pode ter possibilitado, conforme pontuam Geraldi; Fichtner; Benites (2006), que a participante construísse na atividade da sua fantasia as próprias emoções e afetos, desencadeando sentidos positivos para essa experiência. Encontramos em Vigotski (2008b) o entendimento de que cada ideia contém uma atitude afetiva transmutada com relação ao fragmento da realidade ao qual se refere visto a existência de um sistema dinâmico de significados em que $o$ afetivo e o intelectual se unem.

Nesse sentido, a emoção não está isolada do conhecimento da situação que a produz. Contudo, é importante lembrar que essa integração acontece apenas dentro de um sistema cultural. Todo pensamento encerra desejos, necessidades, interesses, emoções e a compreensão do pensamento do outro depende, exatamente, da interação do ouvinte com essa base afetivo-volitiva (Fichtner, 2009). Assim, o mundo das emoções, comumente considerado um obstáculo para a construção do conhecimento, é ele mesmo necessário para essa construção, sendo a força que o movimenta.

\section{Novas Construções Conceituais dos Mecanismos do Crédito e da Publicidade}

A maioria das participantes não compreendia as normas do crédito e o significado consignado no contexto do empréstimo. Ao longo dos encontros, o entendimento do regulamento dessa modalidade de empréstimo causou perturbações nas estruturas iniciais de pensamento das mulheres, configurando a produção de novos conhecimentos que foram sendo utilizados na avaliação de situações de consumo e na tomada de decisões financeiras.

A compreensão do conceito de taxas de juros e a leitura crítica de materiais publicitários contribuíram para posturas mais reflexivas em relação a diferentes situações de consumo de crédito. No reencontro, conforme podemos observar abaixo, uma participante relata um episódio em que lhe foi oferecido um crédito consignado em uma loja para adquirir um computador. 
Participante 2 Eu, é assim eu to pensando bem. Até aconteceu um caso bem importante pra mim essa semana que passou. Meu filho queria comprar um notebook. Fomos lá na Colombo, fomos ver. Achei um lá bem bonitinho, aí tinha lá embutido junto né, de brinde, uma câmera de digital. E o vendedor "patati, patatati”. Espera aí que nós vamos pensar. Chegamos lá no crediário e piorou. Claro que o meu salário muito alto ((tom irônico)), não ia ter para abrir uma prestação. "Ah, quem sabe a senhora faz um consignado." Um consignado, agora sim! ((risos)). A senhora pode tirar quatro mil e não sei o quê, a senhora nos paga à vista e quanto eu ia pagar por mês e "tã, tã, tã". Não, muito obrigada.

((Risos sobrepostos))

Participante 2 Vamos pensar, vamos ver. Juntar um dinheirinho nos meses que vêm, quem sabe a gente não compra à vista? Ficou assim. Mas, se a gente fosse naquele papo, com aquela câmera digital embutida a gente ia se ralar. 14 ou 20 meses. Não, não dá!

Reencontro

Um aspecto que merece ser destacado é o fato de que esse olhar foi se constituindo a medida que as mulheres elaboraram o conceito de juros no contexto do mecanismo do crédito consignado. A partir daí modificaram-se relações conceituais e surgiram novos agrupamentos de sentidos antes desconhecidos na compreensão do funcionamento do crédito e abriram-se possibilidades de ampliação do campo de ação do sujeito.

Em um exercício proposto no sexto encontro do curso, as participantes compararam, em uma publicidade de crédito consignado, diferentes valores de solicitação de empréstimo, o valor mensal debitado do benefício conforme o número de parcelas e o valor final pago ao banco. Esse trabalho possibilitou a reflexão sobre as vantagens e desvantagens dos negócios de crédito consignado para as instituições financeiras e para si mesmas. Algumas narrativas produzidas durante a atividade evidenciam a complexificação da compreensão. Vejamos o diálogo abaixo:

Participante $1 \quad$ Gozado é que eu, cada vez que fiz meus empréstimos, que eu até trouxe aqui hoje uns que eu fiz antigos, e aí, mas eu nunca mesmo me liguei pra isso, que podia voltar com a proposta pra casa pra ver e estudar aquela proposta /

Participante 3 Mas, tem que ter alguém que esclareça.

Participante 2 Eu sempre faço isso/

118 Educação \& Realidade, Porto Alegre, v. 40, n. 1, p. 105-127, jan./mar. 2015. Disponível em: <http://www.ufrgs.br/edu_realidade> 
Participante $1 \quad$ Era isso que eu disse que eu não entendia, o por cento.

Pesq. - Educadora Se a gente pega $\mathrm{R} \$ 4000,00$ em seis vezes o valor total que a gente paga pro banco é $\mathrm{R} \$ 4134,00$.

Participante 3 Hum.

Pesq. -Educadora Se a gente pega os mesmos quatro mil em 60 vezes, que são cinco anos, a gente paga pro banco mais de $\mathrm{R} \$ 7$ 000,00.

Participante 3 Quanto mais vezes mais paga.

Participante 4 Mas agora eu tô entendendo.

Participante $4 \quad$ ((Risos sobrepostos))

Participante $4 \quad$ Porque quando a gente vai pro centro da cidade o que tem de gente oferecendo empréstimo na rua.

Participante $1 \quad$ Uma loucura.

Participante 4 Mas também, os bancos só têm a ganhar.

Encontro 6

Outra atividade importante consistiu em analisar, a partir da sua própria realidade existencial, uma tabela de simulação de crédito, responder em quantas vezes fariam um empréstimo de $\mathrm{R} \$ 4000,00$ e justificar sua resposta. A interação abaixo aconteceu durante a discussão sobre as respostas do exercício.

Pesq. - Educadora Então, eu te pergunto Neide Maria, será que com o que tu ganhas tu poderias fazer o empréstimo em seis vezes?

Participante 2 De seis vezes?

Pesq. - Educadora R\$ 4 000,00 em seis vezes ia ser uma prestação de $\mathrm{R} \$ 689,00$.

Participante 2 Não poderia.

Participante 1 Não pode.

Participante 2 É muito alto né. Nem eles iam me dar né, lá no chefe que é o INSS.

Pesq. - Educadora Por que que tu pegou em seis vezes mesmo?

Participante 2

Eu peguei em seis vezes porque eu pensei que o juro era menos.

09 Pesq. - Educadora Tu não foi ver quanto tiraria do teu dinheiro?

Participante 2

É. Não, isso aí eu não pensei. Eu nem pensei no meu dinheiro né.

Participante 1 É aí que...

Participante 2

Que não ia dá no meu dinheiro né.

Encontro 7 
Educação Financeira com Idosos em um Contexto Popular

Essa situação nos mostra que embora a participante 2 tenha abstraído alguns atributos do mecanismo do crédito - a compreensão das taxas de juros - ela não foi capaz de aplicar, naquele momento, todo o seu novo conhecimento na situação como possível tomadora de crédito. Contudo, durante a atividade, foi confrontada a refletir sobre o seu raciocínio o que desestabilizou seus argumentos. A sua estratégia para resolver o problema proposto no exercício foi posta em xeque, o que permitiu que ela alcançasse um patamar mais elevado de pensamento. Ao ser convidada a explicitar sua própria teoria sobre a resposta formulada no exercício, observou-se uma reestruturação conceitual no pensamento da participante.

Além do conceito de taxas de juros presente nas propostas de crédito consignado, também conversamos sobre as siglas que representam as taxas, como por exemplo, CET (custo efetivo total). As intervenções não tiveram a intenção de que as mulheres se apropriassem dos significados das siglas, mas que elas pudessem refletir sobre a função delas no funcionamento do crédito consignado.

Tendo em vista que a intencionalidade da intervenção educativa foi promover perspectivas mais críticas das situações de consumo, também realizamos de leituras de publicidades de produtos financeiros como o crédito consignado. Os apelos ao consumo são, predominantemente, de ordem subjetiva. Ou seja, para atingir seus objetivos a publicidade utiliza mecanismos que interpelam os sujeitos a consumir, produzindo sonhos e desejos celebrados no imaginário cultural consumista, (re) produzindo, assim, os ideais desta sociedade (Severiano, 2006).

Nesse sentido, o capitalismo pós-industrial produz modos de ser e estar no mundo - tanto em nível de uma macropolítica social quanto de uma micropolítica do desejo que, segundo Guattari; Rolnick (1996), são as estratégias da economia do desejo no campo social - definindo tanto os rumos econômicos, sociais e políticos das sociedades quanto os pequenos gestos do cotidiano.

\section{[...] tudo o que é produzido pela subjetivação capitalística [configuram-se como] sistemas de conexão direta entre as grandes máquinas produtivas, as grandes máquinas de controle social e as instâncias psíquicas que definem a ma- neira de perceber o mundo (Guattarri; Rolnik, 1996, p. 27).}

Uma constatação da potência dos processos de subjetivação na sociedade consumista contemporânea encontra-se no fato de que existem cada vez mais pessoas endividando-se em razão do consumo excessivo. Portanto, a tomada de uma decisão financeira extrapola o nível cognitivo, uma vez que também é regida pela ordem desejo o que implica em lidar com questões do inconsciente.

As estratégias da publicidade se valem da esfera do desejo, subordinando-o a fins mercantis. Dessa forma, ações pedagógicas que pro- 
ponham a interpretação de materiais publicitários podem oportunizar que o sujeito amplie sua compreensão do modo como valores, estilos de vida e normas de conduta são agregados aos bens de consumo.

A análise das publicidades foi realizada por meio de diferentes perguntas que procuraram perturbar as percepções iniciais das mulheres. Por exemplo, analisamos coletivamente uma publicidade de crédito consignado do Banco do Rio Grande do Sul com forte apelo emocional, cujo folder veiculava a imagem de um casal abraçado e com semblante de felicidade. Além disso, constava abaixo da imagem um símbolo estampado com as cores da bandeira do estado com a seguinte mensagem: Governo do Rio Grande do Sul, coragem para fazer. A linguagem publicitária opera no sentido de produzir certos significados e neste caso temos a concepção de coragem, valor comumente atribuído a pessoas fortes e conquistadores, atrelada ao contrato de crédito.

As intervenções iniciais da pesquisadora-educadora foram feitas para instigar o grupo a expressar-se acerca do anúncio publicitário discorrendo sobre suas impressões. Os conteúdos das falas das mulheres indicaram o fascínio exercido pela imagem, que foi associada à beleza, à felicidade, à tranquilidade e do bem-estar. Uma das participantes imaginou-se vivendo a situação do casal, projetando-se na situação em que o crédito seria usado para viajar. A emoção de felicidade surge associada à circunstância de ter dinheiro para gastar.

Em um dado momento, foram realizadas algumas perguntas, como: vamos imaginar esse casal, em que momento será que eles estão rindo? Quando eles vão pegar o crédito? Quando eles já pegaram o crédito? E será que quando eles estão pagando eles estão assim abraçadinhos e sorrindo? Em que momento essa foto foi tirada? O efeito das perguntas foi uma aproximação das mulheres com os seus mundos reais. Desse modo, provocou-se a formulação de outras respostas em relação ao folder que oportunizaram a discussão sobre as situações de contrato de crédito consignado e seus impactos na vida das pessoas idosas. Nesse sentido, Pontecorvo (2005) pontua a importância do mecanismo social desencadeado pelo interlocutor exigente, por aquele que não está satisfeito com o que dizem ou respondem os outros, propondo objeções, perguntas, delimitações, motivando assim o grupo a procurar construir afirmações mais bem fundamentadas.

Cabe, ainda, retomar Giroux $(1990,1995)$ quando aponta para a necessidade de reconhecer que todos os aspectos da política fora dos espaços educativos representam um tipo de pedagogia em que o conhecimento está sempre vinculado ao poder e que as práticas sociais são sempre encarnações de relações concretas entre seres humanos. Portanto, os educadores devem propiciar nos espaços educativos a oportunidade de se examinar diversas linguagens. Assim, ler criticamente as estratégias de sedução da publicidade pode ser um meio de desencadear pensamentos mais complexos em relação às estratégias midiáticas que nos impulsionam a consumir.

Educação \& Realidade, Porto Alegre, v. 40, n. 1, p. 105-127, jan./mar. 2015.

Disponível em: <http://www.ufrgs.br/edu_realidade> 
Por fim, a intervenção educativa procurou desafiar as participantes, em diferentes momentos, a irem se percebendo, como diria Freire (1996), na e pela própria prática, sujeitos capazes de saber. Nesse sentido, será analisada uma das últimas interações entre a pesquisadora-educadora produzida no reencontro do curso:

Pesq. - Educadora Tem uma coisa que minha colega diz, às vezes nas nossas conversas, que eu acho que serve pra gente aqui também. Ela diz que a gente tem que aprender a se fazer mais perguntas na vida. Pode ser que o curso tenha ajudado a aprender a fazer perguntas. É poder chegar lá pra quem tá oferecendo o crédito e pedir pra ele me explicar. Eu quero saber, qual vai ser o valor total final que eu estou pagando? Quanto mais eu vou pagar se eu faço em seis vezes ou em 12 meses? Nós somos consumidoras e temos direito à informação.

Participante 1 Às vezes a gente não vai perguntar por vergonha. Agora não. Agora eu até vou sentar na mesa do gerente.

Pesq. - Educadora Sim.

Participante Amanhãeu volto.

Reencontro

A partir desse diálogo podemos refletir sobre o fato de que quando o sujeito se reconhece como autor dos seus atos e processos de pensamento, ele apropria-se de si e se implica na construção de novas realidades possíveis e viáveis. A partir do incentivo à atitude de perguntar, a participante percorre o caminho da vergonha à mesa do gerente. Ao pronunciar suas palavras, autorizou-se a sentar à mesa do gerente, ocupando outro lugar nas relações de poder. Ao vencer a vergonha produziu novos significados de si mesma. Apropriada desses significados pôde empoderar-se para projetar-se no futuro. Quando ela diz amanhã eu volto refere-se à capacidade de pensar e refletir antes de fazer uma escolha. Assim, transformou a antiga configuração, na qual ocupava a posição de não saber e de ser menos, quando se visualizou ao lado da figura de autoridade. Sonhou em ser mais.

\section{Considerações Finais}

O fenômeno do consumo está assumindo um papel determinante na organização da vida social. Em razão da sua complexidade pode ser abordado por meio de diversos enfoques, sendo que a discussão acerca de intervenções no campo educacional pode ser sustentada por diferentes perspectivas teóricas. Nesse sentido, cabe sinalizar que a proposta da presente pesquisa está circunscrita na análise, em uma dimensão 
cognitiva, da aprendizagem de mulheres idosas em uma ação educativa na qual se procurou problematizar as relações de consumo e o uso do dinheiro.

Portanto, a partir da experiência analisada propõem-se alguns princípios que podem fundamentar intervenções educativas considerando a importância da criação de práticas de educação que oportunizem o protagonismo do consumidor idoso:

1. Desenvolver práticas educativas a partir de uma metodologia dialógica e investigativa para compreender as formas de raciocínio e as atitudes dos idosos em relação ao mercado de consumo. Ou seja, partindo das experiências de consumo vividas pelas pessoas devem-se criar espaços de troca de saberes, de forma que novos sentidos acerca de suas realidades possam ser produzidos em uma (re)leitura crítica do seu mundo e da sua posição nas relações de poder.

2. Conhecer a realidade das pessoas que participam da intervenção educativa, pois as experiências dos educandos devem ser o elemento central da prática pedagógica, tendo como ponto de partida os problemas referentes às suas experiências financeiras. A ação pedagógica deve permitir a observação das problemáticas econômicas do grupo por meio de estratégias, tais como: identificação das principais práticas de consumo dos membros do grupo, classificação e registro de rendas e despesas, realização de exercícios como um orçamento mensal.

3. Identificar os conceitos espontâneos dos sujeitos sobre o uso do dinheiro e práticas de consumo de modo a possibilitar que reflitam sobre suas prioridades. Os conceitos devem ser analisados de modo que possibilitem o afastamento do sujeito para conscientemente percebê-los e (re)significá-los.

4. Utilizar recursos pedagógicos próximos da realidade das pessoas e criar situações hipotéticas como elementos desencadeadores de reflexões sobre as práticas de consumo, tais como exercícios de imaginação, simulações de contratos de empréstimos que fomentem a construção de formas mais complexas de pensamento, ampliando a perspectiva do sujeito tornar compreensível para si a sua experiência.

5. Ler e analisar materiais que circulam na sociedade tais como tabelas de simulação de empréstimos e publicidades em geral, procurando relacioná-los às vivencias concretas dos sujeitos.

6. Criar contextos de aprendizagem em que as pessoas reflitam sobre as suas relações com o dinheiro. Usamos o dinheiro para trocá-lo por alguma coisa. Contudo, quando compramos algo não estamos simplesmente fazendo uma troca, pois fazer uma escolha de consumo envolve uma série de informações de ordem cognitiva, afetiva e financeira, o que torna a decisão singular.

7. Promover a reflexão sobre a facilidade de consumo por meio da problematização do uso de cartões de crédito, da contratação de créditos, como o consignado, ou outras práticas comuns nos contextos 
em que a intervenção estiver sendo realizada - no caso da experiência apresentada cadernetas de vendas, armazéns e vendedores ambulantes. Abordar esses elementos oportuniza que o sujeito compreenda suas experiências, abrindo-se, assim, uma possibilidade para a construção de soluções para suas problemáticas.

Especificamente sobre a abordagem do crédito consignado vale destacar a importância da compreensão das taxas cobradas pelas instituições financeiras. A capacidade de operar com os símbolos abstratos amplia as possibilidades da constituição de novos modos de pensar sobre essa modalidade de empréstimo. Assim, os sujeitos podem melhor avaliar a proposta de um produto financeiro quando conseguem associá-la ao reconhecimento de suas possibilidades financeiras e as prioridades de consumo.

Além disso, reforçamos a perspectiva de que as intervenções educativas financeiras, destinadas a sujeitos adultos e idosos de classes populares, possibilitem a participação daqueles que não se apropriaram da leitura e da escrita ou possuem poucos anos de escolarização. Portanto, as intervenções educativas para o consumo destinadas aos idosos devem ser baseadas na oralidade, sem que isso signifique prescindir do registro escrito, pois diálogo tem uma grande potencialidade de gerar conexões conceituais possibilitando a ampliação da leitura de mundo das pessoas.

No contexto educativo desta pesquisa, procuramos provocar a constituição dos processos de compreensão e de transformação da realidade em um movimento que partiu do concreto e, mediado pelo conceito, retornou ao concreto Nesse sentido, criamos um espaço de descontextualização como pontua Moura, ou seja, “[...] um lugar de experienciar o mundo estando fora dele, onde o concreto tornou-se abstrato, o imediato tornou-se distante" (Moura, 1999, p. 110). E a realidade foi estudada para além da percepção que inicialmente se tinha dela. Assim, apropriado de informações, de conceitos e de sentidos negociados coletivamente, o sujeito passa de um pensar simples para um pensar mais elaborado, engendrando posturas mais reflexivas no enfrentamento das situações de consumo.

Por fim, a relevância de ações educativas voltadas aos idosos, especialmente de classes populares, está exatamente no fortalecimento desses grupos sociais, de forma a produzir deslocamentos de posições de subordinação para posições de autoria da vida. No exemplo dessa pesquisa, trata-se de um público em situação de vulnerabilidade social, constituída e potencializada por fatores que envolvem o nível de escolaridade, a idade, o gênero, a posição de arrimo financeiro da família e a coabitação. Além disso, trata-se de um grupo mais suscetível aos mecanismos do mercado financeiro, em seus diferentes graus de complexidade, que vão desde o uso da caderneta em armazém da vila até o contrato de crédito consignado em grandes instituições financeiras. 


\section{Nota}

1 As mulheres, ao descreverem algumas experiências problemáticas de consumo por meio da expressão "comprar por impulso", localizaram em si a motivação para ação. Nesse sentido, é importante problematizar essa concepção naturalizante que responsabiliza o indivíduo por esse tipo de ação. Portanto, ao longo do texto utilizaremos a palavra impulso entre aspas, compreendendo que na contemporaneidade somos "impulsionados" a consumir por meio de diversas e complexas estratégias, atreladas a produção de desejos, facilidade de obtenção de crédito, das formas infinitas de parcelamentos, entre outras.

\section{Referências}

BAUDRILLARD, Jean. A Sociedade do Consumo. Lisboa: Edições 70, 2007.

BAUMAN, Zygmunt. Vida para Consumo: a transformação das pessoas em mercadoria. Rio de Janeiro: Zahar, 2008.

BAUMAN, Zygmunt. Vida a Crédito: conversas com Citlali Rovirosa-Madraso. Rio de Janeiro: Zahar, 2010.

BRANDÃO, Carlos Rodrigues. A Pesquisa Participante e a Participação da Pesquisa. In: BRANDÃO, Carlos Rodrigues; STRECK, Danilo Romeu (Org.). Pesquisa Participante: a partilha do saber. Aparecida: Idéias \& Letras, 2006. P. 21-54.

BRASIL. Ministério da Previdência Social. Renovação aos 88 anos. Brasília: 2010.

BRASIL. Ministério da Previdência Social. Empréstimo Consignado. Disponível em: <http://www.previdencia.gov.br/conteudoDinamico.php?id=342>. Acesso em: 19 abr. 2013.

BUAES, Caroline Stumpf. Sobre a Construção de Conhecimentos: uma experiência de educação financeira com mulheres idosas em um contexto popular. Porto Alegre: UFRGS, 2011. 260 f. Tese (Doutorado em Educação) - Programa de Pós-Graduação em Educação, Faculdade de Educação, Universidade Federal do Rio Grande do Sul, Porto Alegre, 2011.

CANCLINI, Nestor G. Consumidores e Cidadãos. Rio de Janeiro: UFRJ, 2010.

COSTA, Ângelo Brandelli; HENNIGEN, Inês. Processos de Subjetivação nas Políticas de Defesa do Consumidor: vulnerabilidade e cidadania em questão. Psico, Porto Alegre, v. 41, n. 3, p. 406-413, 2010.

DOLL, Johannes. Elderly Consumer Weakness in 'Withholding Credit'. In: NIEMI, Johanna; RAMSAY, Iain; WHITFORD, William C. (Org.). Consumer Credit, Debt and Bankruptcy. Comparative and International Perspectives. Oxford and Portland: Hart Publishing, 2009. P. 289-306.

DOLL, Johannes; BUAES, Caroline Stumpf. A Inserção Mercadológica de Novos Consumidores: os velhos entram em cena. In: IV ENEC - ENCONTRO NACIONAL DE ESTUDOS DO CONSUMO: NOVOS RUMOS DA SOCIEDADE DE CONSUMO? Rio de Janeiro. Anais... Rio de Janeiro, 2008. CD-ROM.

FICHTNER, Bernd. Introdução na Abordagem Histórico-Cultural de Vygotsky e seus Colaboradores. Porto Alegre. 2009. 107 f. (Texto digitado) 
Educação Financeira com Idosos em um Contexto Popular

FREIRE, Paulo. Pedagogia do Oprimido. 17. ed. Rio de Janeiro: Paz e Terra, 1987.

FREIRE, Paulo. Pedagogia da Esperança: um reencontro com a pedagogia do oprimido. Rio de Janeiro: Paz e Terra, 1992. P. 245.

FREIRE, Paulo. Pedagogia da Autonomia: saberes necessários à prática educativa. São Paulo: Paz e Terra, 1996.

GERALDI, João Wanderley; FICHTNER, Bernd; BENITES, Maria. Transgressões Convergentes: Vigotski, Bakhtin, Bateson. Campinas: Mercado das Letras, 2006.

GIROUX, Henry. Alfabetização e a Pedagogia do Empowerment Político. In: FREIRE, Paulo; MACEDO, Donaldo. Alfabetização: leitura do mundo, leitura da palavra. Rio de Janeiro: Paz e Terra, 1990. P. 1-27.

GIROUX, Henry, A. Praticando Estudos Culturais nas Faculdades de Educação. In: SILVA, Tomaz Tadeu (Org.). Alienígenas na Sala de Aula. Petrópolis: Vozes, 1995. P. 85-103.

GUATTARRI, Felix; ROLNIK, Suely. Micropolítica, Cartografias do Desejo. 4 ed. Petrópolis: Vozes, 1996.

IBGE. Instituto Brasileiro de Geografia e Estatística. Síntese de Indicadores Sociais: Uma Análise das Condições de Vida da População Brasileira. Estudos e Pesquisas Informação Demográfica e Socioeconômica, n. 27. Rio de Janeiro, 2010.

INSS. Instituto Nacional do Seguro Social. Informações da Página do Ministério da Previdência Social. 2008. Disponível em: <www.previdencia.gov.br>. Acesso em: 10 jan. 2008.

INSS. Instituto Nacional Do Seguro Social. Informações da Página do Ministério da Previdência Social. 2009. Disponível em: <http://www.mpas.gov.br/ vejaNoticia.php?id=36850 . Acesso em: 29 set. 2010.

IPEA. Instituto de Pesquisa Econômica Aplicada. PNAD 2009 - Primeiras Análises: situação da educação brasileira - avanços e problemas. Comunicados IPEA n. 66. Ipea, 2010.

IPEA. Instituto de Pesquisa Econômica Aplicada. Tendências Demográficas mostradas pela PNAD 2011. Comunicados IPEA n. 157. Ipea, 2012

IPEA. Instituto de Pesquisa Econômica Aplicada. PNAD 2009 - Primeiras Análises: situação da educação brasileira - avanços e problemas. Comunicados IPEA n. 66. Ipea, 2010.

MARCUSCHI, Luiz Antônio. Análise da Conversação. São Paulo: Ática, 2003.

MOURA, Mayra Patrícia. A Organização Conceitual em Adultos pouco Escolarizados. In: OLIVEIRA, Marcos Barbosa; OLIVEIRA, Marta Kohl (Org.). Investigações Cognitivas: conceitos, linguagem e cultura. Porto Alegre: Artes Médicas Sul, 1999. P. 101-113.

POLI, Solange Maria Alves. Freire e Vigotski: o diálogo entre a pedagogia freireana e a psicologia histórico-cultural. São Paulo: USP, 2007. 205 f. Tese (Doutorado em Educação) - Faculdade de Educação, Universidade de São Paulo, 2007.

PONTECORVO, Clotilde. Discutir, Argumentar e Pensar na Escola. O adulto como Regulador da Aprendizagem. In: PONTECORVO, Clotilde; AJELLO, Anna Maria; Zucchermaglio. Discutindo se Aprende: interação social, conhecimento e escola. Porto Alegre: Artmed, 2005. P. 65-88.

SEVERIANO, Maria de Fátima Vieira. Pseudo-Individuação e Homogeneização na Cultura do Consumo: reflexões críticas sobre as subjetividades contemporâ- 
neas na publicidade. Estudos e Pesquisas em Psicologia, Rio de Janeiro, v. 6 n. 2, dez. 2006.

VEIGA-NETO, Alfredo. As Idades do Corpo: (material)idades, (divers)idades, (corporal)idades, (ident)idades... In: GARCIA, Regina L. O Corpo que Fala Dentro e Fora da Escola. Rio de Janeiro: DP\&A, 2001. P. 35-64.

VIGOTSKI, Lev Semenovich. A Formação Social da Mente: o desenvolvimento dos processos psicológicos superiores. 7. ed. São Paulo: Martins Fontes, 2008a.

VIGOTSKI, Lev Semenovich. Pensamento e Linguagem. 4. ed. São Paulo: Martins Fontes, 2008b.

WILLIAMS, Toni. Empowerment of Whom and for What? Financial Literacy Education and the New Regulation of Consumer Financial Services. Law \& Policy, n. 29, v. 2, p. 226-256, April. 2007.

Caroline Stumpf Buaes é psicóloga pela Universidade de Passo Fundo. Possui mestrado e doutorado em Educação pela Universidade Federal do Rio Grande do Sul. Atualmente, é professora da Escola de Psicologia da Faculdade Meridional. Em suas pesquisas desenvolve temas relacionados ao consumo e endividamento a partir da interface entre Psicologia, Educação e Envelhecimento.

E-mail: carolinebuaes@gmail.com 